\title{
Review
}

Neuropsychobiology

Neuropsychobiology 2018/2019;77:59-66

DOI: $10.1159 / 000494695$
Received: June 5, 2018

Accepted after revision: October 17, 2018

Published online: November 16, 2018

\section{Dandy-Walker Malformation-Like Condition Revealed by Refractory Schizophrenia: A Case Report and Literature Review}

\author{
Maxime Tréhout ${ }^{\mathrm{a}-\mathrm{c}}$ Norbert Zhang ${ }^{\mathrm{d}}$ Marie Blouet $^{\mathrm{d}}$ Alin Borha $^{\mathrm{e}}$ \\ Sonia Dollfus ${ }^{\mathrm{a}-\mathrm{c}}$ \\ ${ }^{a}$ Service de Psychiatrie, CHU de Caen, Caen, France; ${ }^{b}$ UFR de Médecine, UNICAEN, Normandie Université, Caen, \\ France; ' ISTS, UNICAEN, Normandie Université, Caen, France; ${ }^{\mathrm{d}}$ Service de Radiologie, CHU de Caen, Caen, France; \\ eservice de Neurochirurgie, CHU de Caen, Caen, France
}

\section{Keywords}

Schizophrenia - Psychosis - Treatment-resistant

schizophrenia · Cerebellum · Dandy-Walker malformation

\begin{abstract}
Introduction: Dandy-Walker malformation is a rare congenital malformation involving cystic dilatation of the fourth ventricle, enlarged posterior fossa, complete or partial agenesis of the cerebellar vermis, elevated tentorium cerebelli, and hydrocephalus. Previous research highlighted a possible role for the cerebellum in schizophrenia as well as the contribution of underlying brain malformations to treatment resistance. Here, we present a case of a Dandy-Walker malformation-like condition revealed by a refractory schizophrenia in a 24-year-old male patient. We also conduct a literature review of all previously published case reports or case series of co-occurring posterior fossa abnormalities and schizophrenia or psychosis using a PubMed search query to better understand the potential link between these two disorders. Case Presentation: A 9-month hospital stay was needed to address the treatment-resistant psychotic symptoms, and the patient continued to experience moderate symptoms despite the prescription of various antipsychotic
\end{abstract}

(c) 2018 S. Karger AG, Basel

E-Mail karger@karger.com www.karger.com/nps and antidepressant medications. After an irregular initial medical follow-up, the patient is currently treated with 350 mg daily clozapine and $20 \mathrm{mg}$ daily prazepam and still exhibits moderate anxiety without delirious thoughts, however allowing him to re-enroll at the university. Regarding the literature, 24 cases published between 1996 and 2017 were identified, reviewed and compared to the present case report. Discussion: This case report and literature review further illuminates the pathophysiology of psychotic disorders including the potential role of the cerebellum, reinforces the importance of a multidisciplinary approach for the neurological and psychiatric management of patients with schizophrenia, and highlights optimal pharmacological management strategies for treatment-resistant schizophrenia.

(c) 2018 S. Karger AG, Basel

\section{Introduction}

The cerebellum is traditionally involved in the coordination and integration of motor function, but its contributions to the modulation of higher-order functions is also receiving increasing attention [1]. Congenital or acquired posterior fossa malformations including cerebel- 
lar lesions have been associated with cognitive, emotion$\mathrm{al}$, and behavioral disturbances including deficits in executive functions, language disruption, affective disorders, and psychotic features, also known as "cerebellar cognitive-affective syndrome" [2]. Cerebellar structures, especially the vermis, are associated with the pathophysiology of psychiatric disorders including schizophrenia [3-12] and are specifically associated with auditory verbal hallucinations [13] or cognitive dysfunctions [14-16]. Structural and functional cerebellar abnormalities have been observed in schizophrenia $[17,18]$, and smaller cerebellar hemispheres or vermis atrophy have been seen in both first-episode and chronic schizophrenia [11]. The cerebellum is connected to the cerebral cortex by a cortico-cerebellar-thalamic-cortical circuit, which facilitates the automatic modulation of mood and behavior. The majority of functional studies are focused on changes in the fronto-thalamo-cerebellar circuit as theorized by the popular "cognitive dysmetria" model $[3,19]$, which implicates the structure and function of the cerebellum (for meta-analysis, see Bernard and Mittal [20]) and its networks with both the prefrontal and parietal cortices. Disturbed connections within multiple large-scale cerebellar functional networks have also been identified in support of the "disconnectivity hypothesis" in the cortico-cerebellar-thalamic-cortical circuit $[21,22]$.

Dandy-Walker syndrome is a condition of multifactorial origin. It typically arises as a developmental disorder or as the outcome of viral inflammatory disease contracted in utero [23]. The chief etiological factors are hypothesized to be mutations, chromosomal aberrations, mitotic interferences, and altered nucleic acid synthesis. The Dandy-Walker complex (DWC) is a series of rare neurodevelopmental anomalies of the posterior fossa, including Dandy-Walker malformation (DWM) (defined as cystic dilatation of the fourth ventricle, enlarged posterior fossa, complete or partial agenesis of the cerebellar vermis, elevated tentorium cerebelli, and hydrocephalus), Dandy-Walker variant (DWV) (defined as variable hypoplasia of the cerebellar vermis with or without enlargement of the cisterna magna, communication between the fourth ventricle and arachnoid space, and no hydrocephalus), mega cisterna magna (MCM) (defined as an enlarged cisterna magna with integrity of both cerebellar vermis and fourth ventricle), and posterior fossa arachnoid cyst (PFAC) [24-27]. The four subtypes of DWC are believed to occur between the 7 th and 10 th week of gestation [28] and are regarded as a continuum in embryology [29], although they each have unique anatomical characteristics.
Here we present a case of a young man with a DWMlike condition revealed by refractory schizophrenia. We examine the links between severe mental illnesses such as schizophrenia and posterior fossa abnormalities and situate this case within the existing cases of schizophrenia or psychosis and co-occurring DWMs.

\section{Case Report}

A 24-year-old man was admitted to the University Hospital of Caen for his first hospitalization with acute interpretative and persecutory delusions (specifically being followed by secret agents), feelings of insecurity, agitation, disorganized thoughts and behavior, logorrhea, blunted affect, increased emotional feelings (major anxiety and aggression), poor judgment, and severe cognitive deficits. The patient had a history of cannabis abuse beginning at age 15 and increasing over the last 3 years. He had no family history of psychiatric or neurological disorders. His mother suffered from toxoplasmosis and diabetes mellitus during pregnancy, although the patient had an uneventful and normal delivery and achieved normal developmental milestones. He was studying economics at the University but had repeated the second year three times and was unemployed. Premorbid educational and social adjustment were reported as subnormal until age 17, after which symptoms progressively appeared and depressed mood, social withdrawal, anhedonia, avolition, and cognitive impairments began. He was followed by outpatient clinics and reported irregular use of various psychotropic medications, notably antidepressants and anxiolytics with poor adherence. Clinicians initially hypothesized the patient to be at ultra-high risk for psychosis as assessed by the Comprehensive Assessment of At-Risk Mental State, but the complete assessment was unsuccessful due to irregular medical follow-up and dropout from care.

Clinical and biological examinations were normal with no ataxia, nystagmus, or other cerebellar signs. A diagnosis of schizophrenia was established, based on the DSM-5 (Diagnostic and Statistical Manual of Mental Disorders, 5th edition) criteria and structured MINI (Mini International Neuropsychiatric Interview, French version 5.0.0) and according to the patient's symptomatology and history of the disease. Current symptoms were assessed with the Positive and Negative Syndrome Scale (PANSS) and the Brief Psychiatric Rating Scale (BPRS), and the initial scores on admission were $36,25,63$, and 124 for positive, negative, general psychopathology, and total PANSS, respectively. The BPRS score was 74. Neuropsychological testing was not attempted during hospitalization because the patient was unable to participate in cognitive testing, but clinical evaluations highlighted poor sustained and selective attention as well as working memory deficits. Magnetic resonance imaging revealed major tetra-ventricular hydrocephalus and inferior cerebellar vermis hypoplasia with partial agenesis of the left cerebellar hemisphere (Fig. 1). This malformation is described as "DWM-like" in the present case report because DWM was the most likely but incomplete diagnosis. Electroencephalography indicated moderate bioelectric disorganization and hypofunctioning in the prefrontal regions. A neurosurgical shunt was not engaged as there were no signs of intracranial hypertension.
Tréhout/Zhang/Blouet/Borha/Dollfus 

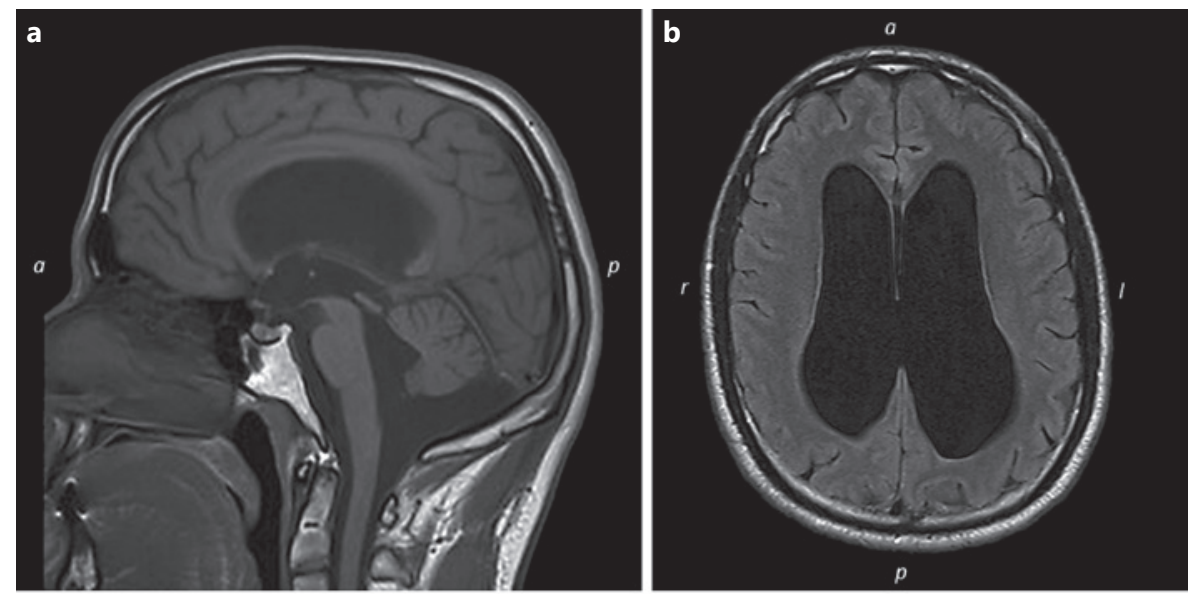

Fig. 1. MR images of the patient. a T1weighted sequence, mid-sagittal slice. Inferior cerebellar vermis hypoplasia, enlargement of the fourth ventricle, normal location of the insertion of the cerebellar tentorium. b T1-weighted sequence, axial slice. Hydrocephalus. c T1-weighted sequence, axial slice. Inferior cerebellar hypoplasia. d T2-weighted sequence, coronal slice. Inferior cerebellar hypoplasia, partial agenesis of the left cerebellar hemisphere, hydrocephalus. a, anterior; $\mathrm{p}$, posterior; $\mathrm{r}$, right; 1, left.
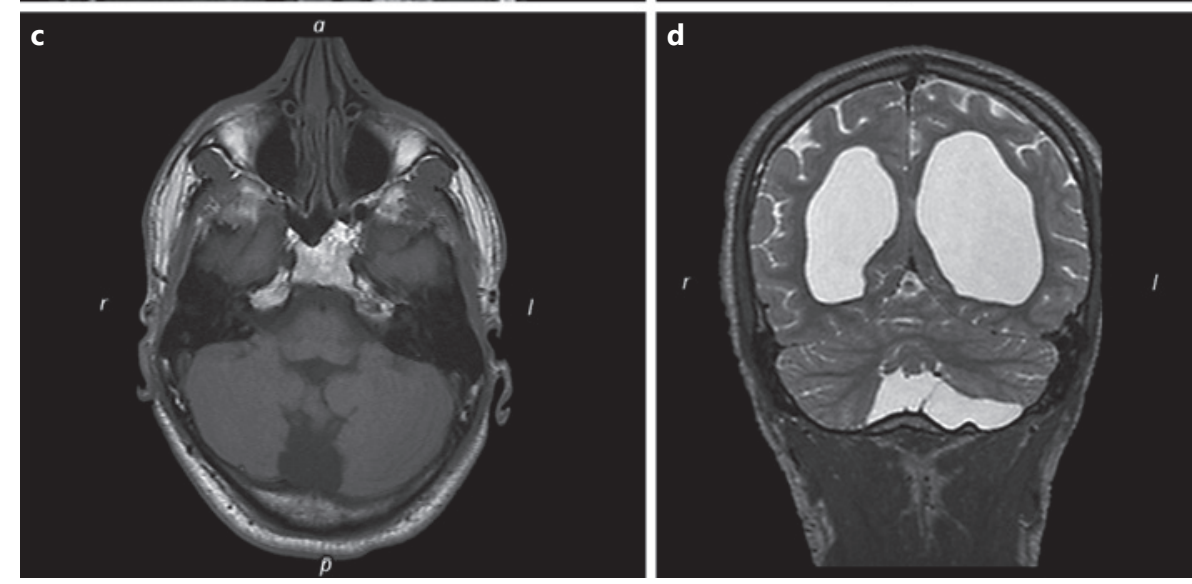

The patient was initially treated with a daily dose of 5 mg olanzapine, which was gradually increased to $30 \mathrm{mg}$. We stopped olanzapine in response to the poor therapeutic response and introduced oral risperidone followed by $150 \mathrm{mg}$ long-acting paliperidone palmitate and saw no clinical response, while risperidone blood levels were under the normal range. The patient was diagnosed with treatment-resistant schizophrenia (TRS) according to TRS guidelines (insufficient response to at least two sequential, different antipsychotic medications of adequate doses taken over an adequate time period) $[30,31]$ after these two antipsychotic medications were found to be ineffective, and was therefore treated with clozapine monotherapy which was gradually increased to $600 \mathrm{mg}$ daily (clozapine and norclozapine blood levels were in the normal range). Psychotic symptomatology initially improved, but persecutive thoughts and anxiety reappeared. We started adjunctive aripiprazole from 10 to $30 \mathrm{mg}$ daily but saw no additional benefits and severe akathisia developed. Aripiprazole was discontinued, and clozapine was given with mirtazapine first at $15 \mathrm{mg}$ and then $30 \mathrm{mg}$ daily, but anxiety still persisted. We switched from mirtazapine to escitalopram which was quickly discontinued because of poor cardiac tolerance and increased QT interval. Antidepressant agents were gradually stopped. A 9-month stay was needed to address the treatment-resistant psychotic symptoms, and the patient continued to experience moderate symptoms including anxiety despite the long hospitalization, the prescription of various antipsychotic and antidepressant medications, and compliance to treatment. PANSS scores at discharge were 16, 16, 41, and 73 for positive, negative, general psychopathology, and total PANSS, respectively. The BPRS score was 40 . Therefore, the patient presented total PANSS and BPRS scores reduced by 41.13 and $45.95 \%$, respectively. The patient was discharged under $600 \mathrm{mg}$ daily clozapine with loxapine as anxiolytic treatment.

An MRI taken 1 year later showed similar and stable results. An ophthalmological examination at 1 year of follow-up was required and revealed no findings related to increased intracranial pressure, such as papilledema, visual loss, or weakness in the lateral rectus muscles. Despite irregular initial medical follow-up, the patient is currently treated with $350 \mathrm{mg}$ daily clozapine and $20 \mathrm{mg}$ daily prazepam and still exhibits moderate anxiety without delirious thoughts; however, this treatment allowed him to re-enroll at the university.

\section{Discussion}

This report focuses on refractory schizophrenia in a patient with DWM-like cerebellar lesions. The concurrence of DWC and psychiatric disorders has occasionally been reported but the association between psychiatric symptoms and DWC remains unclear. We reviewed all 
reported cases of posterior fossa abnormalities associated with schizophrenia or psychosis using a PubMed search query and identified 24 cases in the 18 studies published in the English language between 1996 and 2017. The literature is limited to single case reports or case series of schizophrenia [32-41] or psychosis [23, 42-49] (Table 1). Most cases of schizophrenia were associated with DWV and only one was associated with DWM or MCM. Psychotic cases were generally associated with Dandy-Walker syndrome, MCM, or DWV. Other psychiatric disorders associated with posterior fossa abnormalities include obsessive-compulsive disorder $[33,39,50]$, posttraumatic stress disorder [47], attention deficit hyperkinetic disorders [51, 52], manic episodes [38, 53, 54], bipolar disorder [55-59], impulsive behavior associated with recurrent major depression [60], or recurrent catatonia $[38,61]$.

We used the term DWM-like in the present case report. The diagnostic range of congenital anomalies in the posterior fossa reflects their anatomical predominance and the fact that the classification and the terms "DWM" and "DWV" have been controversial [62]. Advances in genetics and imaging have provided a better understanding of the embryologic origins of these abnormalities [63]. Five entities are commonly described in cases of posterior fossa cystic malformations: DWM, MCM, PFAC, Blake's pouch cyst, and isolated inferior vermian hypoplasia (IIVH). This patient did not present a real complete DWM, specifically due to the absence of a highly positioned cerebellar tentorium but did present an association of nonobstructive malformative hydrocephalus, vermian hypoplasia, and cerebellar hemisphere partial agenesis, termed DWM-like in this report. The vermian hypoplasia associated with hydrocephalus described in this case report is not IIVH, although there is some confusion in the literature about IIVH, and some authors refer to it as DWV. The term DWV lacks specificity and could lead to misdiagnosis, but a case series showed that ex-DWV patients may have hydrocephalus in $24-29 \%$ of cases [64], which can lead to confusion since DWV does not necessarily imply IIVH. Hydrocephalus is occasionally present in cases of Blake's pouch cyst, but the vermis should be normal [62]. MCM is an enlarged cisterna magna with an enlarged posterior fossa in some patients but does not include hydrocephalus. Finally, hydrocephalus is also possible in PFAC but with a normal vermis and fourth ventricle [62]. Additionally, hydrocephalus in the arachnoid cyst is obstructive, which is not the case in the present report.
Our literature search indicated that psychotic symptoms in schizophrenia associated with posterior fossa abnormalities generally do not improve or partially improve but require treatment attempts with several antipsychotic medications, such as risperidone, quetiapine, olanzapine, clozapine, or aripiprazole (Table 1). Poor functional outcome and partial remission with persistent negative or cognitive symptoms are typical. This is consistent with the concept of "cognitive dysmetria," which implicates poor mental coordination of information processing due to dysfunctional cortical-cerebellar circuits $[3,19]$. Only Kvitvik Aune and Bugge [37] showed a prompt clinical response under $2 \mathrm{mg}$ daily risperidone, and Turner et al. [32] showed improvement without medication. While antipsychotics are effective in improving positive symptoms, approximately $20-35 \%$ of patients showed a partial response or no response to standard antipsychotic treatments, indicating TRS $[65,66]$. In the present report, the patient was diagnosed with TRS after treatment attempts with two lines of antipsychotics without clinical improvement. Individuals in this sample are candidates for clozapine, recommended for TRS [67]. However, the response to clozapine is limited and in the range of $30-70 \%$ [68-71]. Patients who are not responsive to clozapine are classified as ultra-resistant schizophrenia patients, and there are no current treatments with consistent efficacy in these cases [72, 73]. Other strategies, including antipsychotics and other pharmacological co-treatments are frequently used in clinical practice, despite a lack of evidence of efficacy [73-77]. In our literature review, only two cases highlighted psychotic symptoms treated by clozapine $[34,48]$ and both revealed a poor outcome. The present patient was treated with clozapine monotherapy and finally showed an improvement of psychotic symptoms, specifically a reduction in total PANSS and BPRS scores of 41.13 and $45.95 \%$, respectively. This case report highlights the importance of clozapine for nonresponding patients in early stages of disease. Kahn et al. [78] recently suggested that clozapine should be used after patients fail a single antipsychotic trial rather than after two different antipsychotics have been tried, as in the current recommendations. Clozapine may also exert a neuroprotective effect by restoring white matter integrity as described in our recently published study [79]. Together these findings support the earlier use of clozapine in the course of schizophrenia.

This case report raised the question of differential diagnosis when substance use disorder and psychiatric and neurological conditions are comorbid [80-82]. First, psychotic disorder due to another medical condition with 
Table 1. Review of case reports of posterior fossa abnormalities associated with schizophrenia or psychosis

\begin{tabular}{|c|c|c|c|c|c|}
\hline Study & $\begin{array}{l}\text { Age, } \\
\text { years/ } \\
\text { gender }\end{array}$ & Clinical diagnosis & $\begin{array}{l}\text { Radiological } \\
\text { diagnosis }\end{array}$ & Treatment strategy & Outcome \\
\hline \multirow[t]{4}{*}{$\begin{array}{l}\text { Pollak et al. } \\
\text { [42], } 1996\end{array}$} & $34 / \mathrm{M}$ & Schizoaffective & $\begin{array}{l}\text { Fourth ventricle } \\
\text { choroid plexus } \\
\text { papilloma }\end{array}$ & Surgery & $\begin{array}{l}\text { No sub- } \\
\text { stantial im- } \\
\text { provement }\end{array}$ \\
\hline & $31 / \mathrm{F}$ & $\begin{array}{l}\text { Brief psychotic } \\
\text { episode }\end{array}$ & $\begin{array}{l}\text { Pontine neuro- } \\
\text { blastoma }\end{array}$ & Surgery & Good \\
\hline & $29 / \mathrm{F}$ & $\begin{array}{l}\text { Schizotypal } \\
\text { personality }\end{array}$ & $\begin{array}{l}\text { Fourth ventricle } \\
\text { tumor, cerebellar } \\
\text { atrophy, ventricle } \\
\text { enlargement }\end{array}$ & Surgery & Poor \\
\hline & $51 / \mathrm{M}$ & Schizoid personality & $\mathrm{MCM}$ & - & Poor \\
\hline $\begin{array}{l}\text { Pradhan et al. } \\
\text { [23], } 1998\end{array}$ & $33 / \mathrm{M}$ & $\begin{array}{l}\text { Psychosis and } \\
\text { epilepsy }\end{array}$ & DW cyst & Carbamazepine $800 \mathrm{mg} /$ day & Good \\
\hline $\begin{array}{l}\text { Turner et al. } \\
{[32], 2001}\end{array}$ & $18 / \mathrm{F}$ & Schizophrenia-like & DWV & No & Good \\
\hline $\begin{array}{l}\text { Ferentinos et al. } \\
{[44], 2007}\end{array}$ & $21 / \mathrm{F}$ & Refractory psychosis & $\mathrm{MCM}$ & Amisulpride $1,200 \mathrm{mg} /$ day + galantamine $8 \mathrm{mg} /$ day & $\begin{array}{l}\text { Partial } \\
\text { remission }\end{array}$ \\
\hline $\begin{array}{l}\text { Papazisis et al. } \\
{[33], 2007}\end{array}$ & 20/M & $\begin{array}{l}\text { Early-onset } \\
\text { schizophrenia }\end{array}$ & DWV & Different types of antipsychotic and antidepressant medication & $\begin{array}{l}\text { Partial } \\
\text { remission }\end{array}$ \\
\hline \multirow[t]{4}{*}{$\begin{array}{l}\text { Gan et al. } \\
{[34], 2012}\end{array}$} & $15 / \mathrm{F}$ & Schizophrenia-like & DWM & Risperidone $4 \mathrm{mg} /$ day + surgery & $\begin{array}{l}\text { Partial } \\
\text { remission }\end{array}$ \\
\hline & $13 / \mathrm{M}$ & Psychosis & DWV & $\begin{array}{l}\text { Sertraline } 50 \mathrm{mg} / \text { day + quetiapine } 400 \mathrm{mg} / \text { day + alprazolam } \\
0.4 \mathrm{mg} / \text { day then sertraline } 50 \mathrm{mg} / \text { day + olanzapine } 2.5 \mathrm{mg} / \text { day + sodium valproate } \\
0.5 / \text { day }\end{array}$ & $\begin{array}{l}\text { Partial } \\
\text { remission }\end{array}$ \\
\hline & $45 / \mathrm{M}$ & Schizophrenia & $\mathrm{MCM}$ & Clozapine $200 \mathrm{mg} /$ day then risperidone $7 \mathrm{mg} /$ day & $\begin{array}{l}\text { Partial } \\
\text { remission }\end{array}$ \\
\hline & 20/M & Psychosis & PFAC & $\begin{array}{l}\text { Duloxetine } 90 \mathrm{mg} / \text { day + olanzapine } 15 \mathrm{mg} / \text { day + clonazepam } \\
2 \mathrm{mg} \text { /day then sodium valproate } 1,200 \mathrm{mg} / \text { day + olanzapine } \\
20 \mathrm{mg} / \text { day }\end{array}$ & $\begin{array}{l}\text { Partial } \\
\text { remission }\end{array}$ \\
\hline $\begin{array}{l}\text { Ryan et al. } \\
{[45], 2012}\end{array}$ & $14 / \mathrm{F}$ & $\begin{array}{l}\text { New-onset } \\
\text { psychosis }\end{array}$ & DWV & Risperidone $2.25 \mathrm{mg} /$ day + escitalopram & Good \\
\hline $\begin{array}{l}\text { Sidana et al. } \\
{[35], 2013}\end{array}$ & 20/M & Schizophrenia & DWV & $\begin{array}{l}\text { Olanzapine } 10 \mathrm{mg} / \text { day then aripiprazole } 10 \mathrm{mg} / \text { day then } \\
2.5 \mathrm{mg} / \text { day }\end{array}$ & Good \\
\hline $\begin{array}{l}\text { Bozkurt Zincir } \\
\text { et al. } 2014[36]\end{array}$ & $30 / \mathrm{F}$ & Schizophrenia-like & DWV & $\begin{array}{l}\text { Risperidone depot } 50 \mathrm{mg}+6 \mathrm{mg} / \text { day p.o. + biperiden } 4 \mathrm{mg} / \text { day + lorazepam } 2.5 \mathrm{mg} / \\
\text { day }\end{array}$ & $\begin{array}{l}\text { Partial } \\
\text { remission }\end{array}$ \\
\hline $\begin{array}{l}\text { Buonaguo et al. } \\
{[46], 2014}\end{array}$ & $29 / \mathrm{F}$ & Schizophrenia-like & DWS & $\begin{array}{l}\text { Lithium + valproate then risperidone then valproate + pimozide then haloperidol + } \\
\text { valproate then valproate } 750 \mathrm{mg} / \text { day + haloperidol } 4 \mathrm{mg} / \text { day + biperiden } 4 \mathrm{mg} / \text { day }\end{array}$ & Poor \\
\hline $\begin{array}{l}\text { Kvitvik Aune } \\
\text { et al. [37], } 2014\end{array}$ & $22 / \mathrm{M}$ & Schizophrenia & DWV & Risperidone $2 \mathrm{mg} /$ day & Good \\
\hline $\begin{array}{l}\text { Mauritz et al. } \\
{[47], 2014}\end{array}$ & $47 / \mathrm{F}$ & Psychosis & DWS & $\begin{array}{l}\text { Amitryptyline } 50 \mathrm{mg} / \text { day then amitriptyline + topiramate } \\
50 \mathrm{mg} / \text { day then surgery + quetiapine } 600 \mathrm{mg} / \text { day }\end{array}$ & Good \\
\hline $\begin{array}{l}\text { Pandurangi } \\
\text { et al. [38], } 2014\end{array}$ & 20/M & $\begin{array}{l}\text { Catatonic } \\
\text { schizophrenia }\end{array}$ & $\mathrm{MCM}$ & Risperidone $3 \mathrm{mg} /$ day & - \\
\hline $\begin{array}{l}\text { Blaettner et al. } \\
{[39], 2015}\end{array}$ & 19/M & Schizophrenia & DWV & $\begin{array}{l}\text { Risperidone } 4 \mathrm{mg} / \text { day then aripiprazole } 30 \mathrm{mg} / \text { day then } \\
\text { amisulpride } 800 \mathrm{mg} \text { then olanzapine } 30 \mathrm{mg} / \text { day then } \\
\text { ziprasidone } 120 \mathrm{mg} / \text { day then ziprasidone } 120 \mathrm{mg} / \text { day + } \\
\text { trazodone } 150 \mathrm{mg} / \text { day }\end{array}$ & $\begin{array}{l}\text { Partial } \\
\text { remission }\end{array}$ \\
\hline $\begin{array}{l}\text { Williams et al. } \\
\text { [48], } 2016\end{array}$ & $20 / \mathrm{F}$ & New-onset psychosis & DWV & $\begin{array}{l}\text { Risperidone then haloperidol } 7 \mathrm{mg} \text { /day then benztropine } 1 \mathrm{mg} \text { bid then aripiprazole } \\
20 \mathrm{mg} / \text { day then ziprasidone } 20 \mathrm{mg} / \text { day then valproate } 500 \mathrm{mg} \text { qhs then clonazepam } \\
0.5 \mathrm{mg} \text { qhs then lorazepam } 1 \mathrm{mg} \text { tid then trazodone } 75 \mathrm{mg} \text { then olanzapine } \\
20 \mathrm{mg} / \text { day then injectable aripiprazole } 400 \mathrm{mg} / \text { month then paliperidone palmitate } \\
156 \mathrm{mg} / \mathrm{month}\end{array}$ & $\begin{array}{l}\text { Partial } \\
\text { remission }\end{array}$ \\
\hline $\begin{array}{l}\text { Dawra et al. } \\
\text { [49], } 2017\end{array}$ & $18 / \mathrm{M}$ & Psychosis & DWS & $\begin{array}{l}\text { Sodium phenytoin } 300 \mathrm{mg} / \mathrm{day}+\text { ondansetron } 8 \mathrm{mg} / \text { day + pantoprazole } 40 \mathrm{mg} / \text { day + } \\
\text { carbamazepine } 600 \mathrm{mg} / \text { day then risperidone } 2 \mathrm{mg} / \text { day + trihexyphenidyl } 2 \mathrm{mg} / \text { day }\end{array}$ & $\begin{array}{l}\text { Partial } \\
\text { remission } \\
\text { and no } \\
\text { follow-up }\end{array}$ \\
\hline $\begin{array}{l}\text { Isidro-Garcia } \\
\text { et al. [40], } 2017\end{array}$ & $34 / \mathrm{F}$ & Refractory psychosis & DWV & $\begin{array}{l}\text { Olanzapine } 20 \mathrm{mg} / \text { day then olanzapine } 20 \mathrm{mg} / \text { day + haloperidol } 10 \mathrm{mg} / \text { day then } \\
\text { paliperidone } 12 \mathrm{mg} / \text { day + haloperidol } \\
10 \mathrm{mg} / \text { day then haloperidol } 5 \mathrm{mg} / \text { day + clozapine } 600 \mathrm{mg} / \text { day }\end{array}$ & Poor \\
\hline $\begin{array}{l}\text { Sinha et al. } \\
{[41], 2017}\end{array}$ & $25 / \mathrm{M}$ & Schizophrenia & DWV & Olanzapine $15 \mathrm{mg} /$ day & $\begin{array}{l}\text { Partial } \\
\text { remission }\end{array}$ \\
\hline
\end{tabular}

F, female; bid, twice a day; M, male; MCM, mega cisterna magna; DWC, Dandy-Walker complex; DWM, Dandy-Walker malformation; DWS, Dandy-Walker syndrome; PFAC, posterior fossa arachnoid cyst; qhs, every night at bedtime; tid, three times a day. 
delusions according to DSM-5 criteria (293.81 [F06.2]) was a possibility. However, there was no evidence from the patient's history, physical examination, or laboratory/ imaging findings suggesting that the psychosis was a direct pathophysiological consequence of a neural condition such as DWM-like, even though the link has been previously described. There was no temporal association with the onset or exacerbation of DWM-like, which is known to be a congenital malformation, and which had been stable over the years as reflected by the patient's normal neurological examination. Psychiatric disturbances including affective and cognitive symptoms appeared only at 17 years of age and could be classified as prodromal symptoms, and psychotic symptoms followed at 24 years. There were no other atypical features related to the psychotic disorder (the age at onset was compatible with schizophrenia, and there were no isolated visual or olfactory hallucinations). Finally, the present review highlights a possible link between the two conditions, but further research is needed. Second, cannabis use has been associated with a significantly increased risk of the subsequent development of psychotic symptoms in the literature [83-85]. Therefore, cannabis-induced psychotic disorder with onset during intoxication (292.9 [F12.959]) or substance withdrawal with perceptual disturbances (292.89 [F12.222]) could be considered as another differential diagnosis according to the DSM-5. However, this diagnosis was discarded because patient's psychotic symptoms were not temporally related to substance intoxication or withdrawal, although cannabis use since 15 years of age and a recent increase in use could otherwise explain the apparition or exacerbation of the patient's cognitive deficits despite subnormal premorbid cognitive and social functioning [86-88]. It appears that both psychotic episodes and cannabis use during a time when the brain has not fully developed can have detrimental effects in the long term [88]. Cannabis use may also contribute to or precipitate the onset of the illness and can predict adverse outcomes, including higher relapse rates, longer hospital admissions, more severe positive symptoms, and treatment resistance [89]. This illustrates the diathesisstress-support model of schizophrenia in which biogenetic and psychosocial factors interact in a vulnerabilitystress model [90-92]. Therefore, organicity, specifically DWM-like in this case, and cannabis use do not prevent the establishment of a schizophrenia diagnosis.

In conclusion, a DWM-like condition was revealed by a refractory schizophrenia in the present case report. Although the association of the two disorders may be coincidental, many studies suggest a potential or direct link between psychotic symptoms and posterior fossa abnormalities that could indicate a causal relationship. Neuroimaging may provide complementary information in cases of treatment-resistant psychosis, even in the absence of neurological symptoms. This case could help illuminate the pathophysiology of psychotic disorders, including the possible role of the cerebellum. It also reinforces the importance of a multidisciplinary neurological and psychiatric approach in the overall management of patients with schizophrenia and highlights various optimal pharmacological management strategies for TRS.

\section{Disclosure Statement}

The authors declare that they have no conflicts of interest.

\section{References}

1 Schmahmann JD. An emerging concept. The cerebellar contribution to higher function. Arch Neurol. 1991 Nov;48(11):1178-87.

2 Schmahmann JD, Sherman JC. The cerebellar cognitive affective syndrome. Brain. 1998 Apr;121(Pt 4):561-79.

3 Andreasen NC, Paradiso S, O'Leary DS. "Cognitive dysmetria" as an integrative theory of schizophrenia: a dysfunction in corticalsubcortical-cerebellar circuitry? Schizophr Bull. 1998;24(2):203-18.

4 DeLisi LE, Sakuma M, Tew W, Kushner M, Hoff AL, Grimson R. Schizophrenia as a chronic active brain process: a study of progressive brain structural change subsequent to the onset of schizophrenia. Psychiatry Res. 1997 Jul;74(3):129-40.
5 Ichimiya T, Okubo Y, Suhara T, Sudo Y. Reduced volume of the cerebellar vermis in neuroleptic-naive schizophrenia. Biol Psychiatry. 2001 Jan;49(1):20-7.

6 Okugawa G, Sedvall G, Nordström M, Andreasen N, Pierson R, Magnotta V, et al. Selective reduction of the posterior superior vermis in men with chronic schizophrenia. Schizophr Res. 2002 May;55(1-2):61-7.

7 Okugawa G, Sedvall GC, Agartz I. Smaller cerebellar vermis but not hemisphere volumes in patients with chronic schizophrenia. Am J Psychiatry. 2003 Sep;160(9):1614-7.

8 Schmahmann JD. Disorders of the cerebellum: ataxia, dysmetria of thought, and the cerebellar cognitive affective syndrome. J Neuropsychiatry Clin Neurosci. 2004;16(3):367-78.
9 Okugawa G, Nobuhara K, Takase K, Kinoshita T. Cerebellar posterior superior vermis and cognitive cluster scores in drug-naive patients with first-episode schizophrenia. Neuropsychobiology. 2007;56(4):216-9.

10 Andreasen NC, Pierson R. The role of the cerebellum in schizophrenia. Biol Psychiatry. 2008 Jul;64(2):81-8.

11 Hoppenbrouwers SS, Schutter DJ, Fitzgerald $\mathrm{PB}$, Chen R, Daskalakis ZJ. The role of the cerebellum in the pathophysiology and treatment of neuropsychiatric disorders: a review. Brain Res Brain Res Rev. 2008 Nov;59(1): 185-200. 
12 Picard H, Amado I, Mouchet-Mages S, Olié JP, Krebs MO. The role of the cerebellum in schizophrenia: an update of clinical, cognitive, and functional evidences. Schizophr Bull. 2008 Jan;34(1):155-72.

13 Cierpka M, Wolf ND, Kubera KM, Schmitgen MM, Vasic N, Frasch K, et al. Cerebellar Contributions to Persistent Auditory Verbal Hallucinations in Patients with Schizophrenia. Cerebellum. 2017 Dec;16(5-6):964-72.

14 Schmahmann JD. The role of the cerebellum in cognition and emotion: personal reflections since 1982 on the dysmetria of thought hypothesis, and its historical evolution from theory to therapy. Neuropsychol Rev. 2010 Sep;20(3):236-60.

15 Shakiba A. The role of the cerebellum in neurobiology of psychiatric disorders. Neurol Clin. 2014 Nov;32(4):1105-15.

16 Mothersill O, Knee-Zaska C, Donohoe G. Emotion and Theory of Mind in Schizophrenia-Investigating the Role of the Cerebellum. Cerebellum. 2016 Jun;15(3):357-68.

17 Laidi C, d'Albis MA, Wessa M, Linke J, Phillips ML, Delavest M, et al. Cerebellar volume in schizophrenia and bipolar I disorder with and without psychotic features. Acta Psychiatr Scand. 2015 Mar; 131(3):223-33.

18 Lungu O, Barakat M, Laventure S, Debas K, Proulx S, Luck D, et al. The incidence and nature of cerebellar findings in schizophrenia: a quantitative review of fMRI literature. Schizophr Bull. 2013 Jul;39(4):797-806.

19 Andreasen NC, O'Leary DS, Cizadlo T, Arndt S, Rezai K, Ponto LL, et al. Schizophrenia and cognitive dysmetria: a positron-emission tomography study of dysfunctional prefrontalthalamic-cerebellar circuitry. Proc Natl Acad Sci USA. 1996 Sep;93(18):9985-90.

20 Bernard JA, Mittal VA. Dysfunctional Activation of the Cerebellum in Schizophrenia: A Functional Neuroimaging Meta-Analysis. Clin Psychol Sci. 2015 Jul;3(4):545-66.

21 Matsuo K, Chen SH, Liu CM, Liu CC, Hwang TJ, Hsieh $\mathrm{MH}$, et al. Stable signatures of schizophrenia in the cortical-subcortical-cerebellar network using fMRI of verbal working memory. Schizophr Res. 2013 Dec;151(1-3): $133-40$.

22 Peters H, Shao J, Scherr M, Schwerthöffer D, Zimmer C, Förstl H, et al. More Consistently Altered Connectivity Patterns for Cerebellum and Medial Temporal Lobes than for Amygdala and Striatum in Schizophrenia. Front Hum Neurosci. 2016 Feb;10:55.

23 Pradhan SC, Das J, Sinha VK. Dandy-walker syndrome with epilepsy and psychosis: an atypical presentation. Indian $\mathrm{J}$ Psychiatry. 1998 Apr;40(2):189-91.

24 Barkovich AJ, Kjos BO, Norman D, Edwards MS. Revised classification of posterior fossa cysts and cystlike malformations based on the results of multiplanar MR imaging. AJR Am J Roentgenol. 1989 Dec;153(6):1289-300.
25 Kollias SS, Ball WS Jr, Prenger EC. Cystic malformations of the posterior fossa: differential diagnosis clarified through embryologic analysis. Radiographics. 1993 Nov;13(6):1211-31.

26 ten Donkelaar HJ, Lammens M, Wesseling P, Thijssen HO, Renier WO. Development and developmental disorders of the human cerebellum. J Neurol. 2003 Sep;250(9):1025-36.

27 Parisi MA, Dobyns WB. Human malformations of the midbrain and hindbrain: review and proposed classification scheme. Mol Genet Metab. 2003 Sep-Oct;80(1-2):36-53.

28 Raybaud C. Cystic malformations of the posterior fossa. Abnormalities associated with the development of the roof of the fourth ventricle and adjacent meningeal structures. J Neuroradiol. 1982;9(2):103-33.

29 Utsunomiya H, Yamashita S, Takano K, Ueda Y, Fujii A. Midline cystic malformations of the brain: imaging diagnosis and classification based on embryologic analysis. Radiat Med. 2006 Jul;24(6):471-81.

30 Howes OD, McCutcheon R, Agid O, de Bartolomeis A, van Beveren NJ, Birnbaum ML, et al. Treatment-Resistant Schizophrenia: Treatment Response and Resistance in Psychosis (TRRIP) Working Group Consensus Guidelines on Diagnosis and Terminology. Am J Psychiatry. 2017 Mar;174(3):216-29.

31 Remington $\mathrm{G}$, Addington $\mathrm{D}$, Honer W, Ismail Z, Raedler T, Teehan M. Guidelines for the Pharmacotherapy of Schizophrenia in Adults. Can J Psychiatry. 2017 Sep;62(9):604-16.

32 Turner SJ, Poole R, Nicholson MR, Ghadiali EJ. Schizophrenia-like psychosis and DandyWalker variant. Schizophr Res. 2001 Mar; 48(2-3):365-7.

33 Papazisis G, Mastrogianni A, Karastergiou A. Early-onset schizophrenia and obsessivecompulsive disorder in a young man with Dandy-Walker variant. Schizophr Res. 2007 Jul;93(1-3):403-5.

34 Gan Z, Diao F, Han Z, Li K, Zheng L, Guan N, et al. Psychosis and Dandy-Walker complex: report of four cases. Gen Hosp Psychiatry. 2012 Jan-Feb;34(1):102.e7-11.

35 Sidana A, Sarkar S, Balasundaram S, Praharaj SK. Increased sensitivity to atypical antipsychotics in a patient with Dandy-Walker variant with schizophrenia. J Neuropsychiatry Clin Neurosci. 2013;25(3):E31-2.

36 Bozkurt Zincir S, Kıvılcım Y, Izci F, Semiz UB. Schizophrenia-like psychosis and dandywalker variant comorbidity: case report. Psychiatry Investig. 2014 Jan;11(1):102-4.

37 Kvitvik Aune I, Bugge E. Schizophrenia in a young man with Dandy-Walker variant. Biol Psychiatry. 2014 Mar;75(5):e9-10.

38 Pandurangi S, Pandurangi A, Matkar A, Shetty N, Patil P. Psychiatric manifestations associated with mega cisterna magna. J Neuropsychiatry Clin Neurosci. 2014 Apr;26(2):16971.

39 Blaettner C, Pfaffenberger NM, Cartes-Zumelzu F, Hofer A. Psychiatric misdiagnoses in Dandy-Walker variant. Neurocase. 2015; 21(4):499-500.
40 Isidro-García GJ, Espina-Barrio JA, GuitiánDomínguez M. Dandy-Walker variant and refractory psychosis. Actas Esp Psiquiatr. $2017 \mathrm{Jul} ; 45(4): 179-84$.

41 Sinha P, Tarwani J, Kumar P, Garg A. DandyWalker Variant with Schizophrenia: Comorbidity or Cerebellar Cognitive Affective Syndrome? Indian J Psychol Med. 2017 Mar-Apr; 39(2):188-90.

42 Pollak L, Klein C, Rabey JM, Schiffer J. Posterior fossa lesions associated with neuropsychiatric symptomatology. Int $J$ Neurosci. 1996 Nov;87(3-4):119-26.

43 Langarica M, Peralta V. [Psychosis associated to megacisterna magna]. An Sist Sanit Navar. 2005 Jan-Mar;28(1):119-21.

44 Ferentinos PP, Kontaxakis VP, Havaki-Kontaxaki BJ, Paplos KG, Pappa DA, Soldatos CR. Refractory psychosis and prominent cognitive deficits in a patient with mega-cisterna magna. Prog Neuropsychopharmacol Biol Psychiatry. 2007 Mar;31(2):561-3.

45 Ryan M, Grenier E, Castro A, Nemeroff CB. New-onset psychosis associated with dandywalker variant in an adolescent female patient. J Neuropsychiatry Clin Neurosci. 2012; 24(2):241-6

46 Buonaguro EF, Cimmarosa S, de Bartolomeis A. Dandy-Walker syndrome with psychotic symptoms: a case report. Riv Psichiatr. 2014 Mar-Apr;49(2):100-2.

47 Mauritz MW, van de Sande R, Goossens PJ, van Achterberg T, Draijer N. Phase-based treatment of a complex severely mentally ill case involving complex posttraumatic stress disorder and psychosis related to Dandy Walker syndrome. J Trauma Dissociation. 2014;15(5):588-606.

48 Williams AJ, Wang Z, Taylor SF. Atypical psychotic symptoms and Dandy-Walker variant. Neurocase. 2016 Oct;22(5):472-5.

49 Dawra RD, Karia S, Shah N, Desousa A. Psychosis in a Case of Dandy-Walker Syndrome: A Case Report. J Clin Diagn Res. 2017 May; 11(5):VD03-04.

50 Rohanachandra YM, Dahanayake DM, Wijetunge S. Dandy-Walker Malformation Presenting with Psychological Manifestations. Case Rep Psychiatry. 2016;2016:9104306.

51 Prakash R, Singh LK, Kour J, Mishra B, Lakra A. Psychiatric comorbidities in Dandy-Walker variant disorder. J Neuropsychiatry Clin Neurosci. 2009;21(4):477-9.

52 Schevenels S, Klockaerts C. [Megacisterna magna as incidental finding in a boy with ADHD]. Tijdschr Psychiatr. 2016;58(9):6558.

53 Turan T, Beşirli A, Asdemir A, Ozsoy S, Eşel E. Manic episode associated with mega cisterna magna. Psychiatry Investig. $2010 \mathrm{Dec} ; 7(4)$ : 305-7.

54 Baliyan S, Arya A, Kar SK. Treatment-resistant mania in Dandy-Walker malformation with seizure disorder: A case report. J Pediatr Neurosci. 2015 Oct-Dec;10(4):413-4.
Refractory Schizophrenia and Neurological Malformation
Neuropsychobiology 2018/2019;77:59-66 DOI: $10.1159 / 000494695$ 
55 Lingeswaran A, Barathi D, Sharma G. DandyWalker variant associated with bipolar affective disorder. J Pediatr Neurosci. 2009 Jul; 4(2):131-2.

56 Bakhla AK, Sarkhel S, Kumar R. Bipolar I disorder in a patient with Dandy-Walker malformation. Psychiatry Clin Neurosci. 2010 Apr; 64(2):212-3.

57 Aimua F, Dunn NR, Swift RG. Dandy walker variant with treatment-resistant bipolar disorder. J Neuropsychiatry Clin Neurosci. 2012; 24(1):E50.

58 Can SS, Karakaş Uğurlu G, Cakmak S. Dandy walker variant and bipolar I disorder with graphomania. Psychiatry Investig. 2014 Jul; 11(3):336-9.

59 Eslami Shahre Babaki M, Estilaee F. Bipolar Disorder in a Young Girl with Dandy-Walker Syndrome. Iran J Psychiatry. 2015 Jun;10(3): 212-3.

$60 \mathrm{Kim} \mathrm{JH}$, Kim TH, Choi YC, Chung SC, Moon SW. Impulsive behavior and recurrent major depression associated with dandy-walker variant. Psychiatry Investig. 2013 Sep;10(3): 303-5.

61 Kumar S, Sur S, Singh A. Mega cisterna magna associated with recurrent catatonia: a case report. Biol Psychiatry. 2011 Aug;70(4):e19.

62 Bosemani T, Orman G, Boltshauser E, Tekes A, Huisman TA, Poretti A. Congenital abnormalities of the posterior fossa. Radiographics. 2015 Jan-Feb;35(1):200-20.

63 Cotes C, Bonfante E, Lazor J, Jadhav S, Caldas $\mathrm{M}$, Swischuk L, et al. Congenital basis of posterior fossa anomalies. Neuroradiol J. 2015 Jun;28(3):238-53.

64 Sasaki-Adams D, Elbabaa SK, Jewells V, Carter L, Campbell JW, Ritter AM. The DandyWalker variant: a case series of 24 pediatric patients and evaluation of associated anomalies, incidence of hydrocephalus, and developmental outcomes. J Neurosurg Pediatr. 2008 Sep;2(3):194-9.

65 Sheitman BB, Lieberman JA. The natural history and pathophysiology of treatment resistant schizophrenia. J Psychiatr Res. 1998 May-Aug;32(3-4):143-50.

66 Lindenmayer JP. Treatment refractory schizophrenia. Psychiatr Q. 2000;71(4):37384.

67 Chung C, Remington G. Predictors and markers of clozapine response. Psychopharmacology (Berl). 2005 May;179(2):317-35.

68 Buchanan RW, Breier A, Kirkpatrick B, Ball P, Carpenter WT Jr. Positive and negative symptom response to clozapine in schizophrenic patients with and without the deficit syndrome. Am J Psychiatry. 1998 Jun;155(6): 751-60.
69 Chakos M, Lieberman J, Hoffman E, Bradford D, Sheitman B. Effectiveness of second-generation antipsychotics in patients with treatment-resistant schizophrenia: a review and meta-analysis of randomized trials. Am J Psychiatry. 2001 Apr;158(4):518-26.

70 Conley RR, Kelly DL. Management of treatment resistance in schizophrenia. Biol Psychiatry. 2001 Dec;50(11):898-911.

71 Kane J, Honigfeld G, Singer J, Meltzer H. Clozapine for the treatment-resistant schizophrenic. A double-blind comparison with chlorpromazine. Arch Gen Psychiatry. 1988 Sep;45(9):789-96.

72 Cipriani A, Boso M, Barbui C. Clozapine combined with different antipsychotic drugs for treatment resistant schizophrenia. Cochrane Database Syst Rev. 2009 Jul;(3):CD006324.

73 Sommer IE, Begemann MJ, Temmerman A, Leucht S. Pharmacological augmentation strategies for schizophrenia patients with insufficient response to clozapine: a quantitative literature review. Schizophr Bull. 2012 Sep;38(5):1003-11.

74 Davis JM. The choice of drugs for schizophrenia. N Engl J Med. 2006 Feb;354(5):518-20.

75 Honer WG, Thornton AE, Chen EY, Chan RC, Wong JO, Bergmann A, et al.; Clozapine and Risperidone Enhancement (CARE) Study Group. Clozapine alone versus clozapine and risperidone with refractory schizophrenia. N Engl J Med. 2006 Feb;354(5):47282.

76 Paton C, Whittington C, Barnes TR. Augmentation with a second antipsychotic in patients with schizophrenia who partially respond to clozapine: a meta-analysis. J Clin Psychopharmacol. 2007 Apr;27(2):198-204.

77 Porcelli S, Balzarro B, Serretti A. Clozapine resistance: augmentation strategies. Eur Neuropsychopharmacol. 2012 Mar;22(3):165-82.

78 Kahn RS, Winter van Rossum I, Leucht S, McGuire P, Lewis SW, Leboyer M, et al.; OPTiMiSE study group. Amisulpride and olanzapine followed by open-label treatment with clozapine in first-episode schizophrenia and schizophreniform disorder (OPTiMiSE): a three-phase switching study. Lancet Psychiatry. 2018 Oct;5(10):797-807.

79 Leroux E, Vandevelde A, Tréhout M, Dollfus S. Abnormalities of fronto-subcortical pathways in schizophrenia and the differential impacts of antipsychotic treatment: a DTI-based tractography study. Psychiatry Res Neuroimaging. 2018 Oct;280:22-9.

80 Benjamin S, Lauterbach MD, Stanislawski AL. Congenital and acquired disorders presenting as psychosis in children and young adults. Child Adolesc Psychiatr Clin N Am. 2013 Oct;22(4):581-608.
81 Giannitelli M, Consoli A, Raffin M, Jardri R, Levinson DF, Cohen D, et al. An overview of medical risk factors for childhood psychosis: implications for research and treatment. Schizophr Res. 2018 Feb;192:39-49.

82 Lieberman JA, First MB. Psychotic Disorders. N Engl J Med. 2018 Jul 19;379(3):270-80.

83 Murray RM, Englund A, Abi-Dargham A, Lewis DA, Di Forti M, Davies C, et al. Cannabis-associated psychosis: neural substrate and clinical impact. Neuropharmacology. 2017 Sep;124:89-104.

84 Murray RM, Bhavsar V, Tripoli G, Howes O. 30 Years on: How the Neurodevelopmental Hypothesis of Schizophrenia Morphed Into the Developmental Risk Factor Model of Psychosis. Schizophr Bull. 2017 Oct 21;43(6): 1190-6.

85 Starzer MS, Nordentoft M, Hjorthøj C. Rates and Predictors of Conversion to Schizophrenia or Bipolar Disorder Following SubstanceInduced Psychosis. Am J Psychiatry. 2018 Apr;175(4):343-50.

86 Leeson VC, Harrison I, Ron MA, Barnes TR, Joyce EM. The effect of cannabis use and cognitive reserve on age at onset and psychosis outcomes in first-episode schizophrenia. Schizophr Bull. 2012 Jun;38(4):873-80.

87 Ferraro L, Russo M, O'Connor J, Wiffen BD, Falcone MA, Sideli L, et al. Cannabis users have higher premorbid IQ than other patients with first onset psychosis. Schizophr Res. 2013 Oct;150(1):129-35.

88 Bogaty SE, Lee RS, Hickie IB, Hermens DF. Meta-analysis of neurocognition in young psychosis patients with current cannabis use. J Psychiatr Res. 2018 Apr;99:22-32.

89 Schoeler T, Monk A, Sami MB, Klamerus E, Foglia E, Brown R, et al. Continued versus discontinued cannabis use in patients with psychosis: a systematic review and meta-analysis. Lancet Psychiatry. 2016 Mar;3(3):215-25.

90 Cheng SC, Walsh E, Schepp KG. Vulnerability, Stress, and Support in the Disease Trajectory from Prodrome to Diagnosed Schizophrenia: Diathesis-Stress-Support Model. Arch Psychiatr Nurs. 2016 Dec;30(6):810-7.

91 Howes OD, McCutcheon R. Inflammation and the neural diathesis-stress hypothesis of schizophrenia: a reconceptualization. Transl Psychiatry. 2017 Feb 7;7(2):e1024.

92 Pruessner M, Cullen AE, Aas M, Walker EF. The neural diathesis-stress model of schizophrenia revisited: an update on recent findings considering illness stage and neurobiological and methodological complexities. Neurosci Biobehav Rev. 2017 Feb;73:191218 